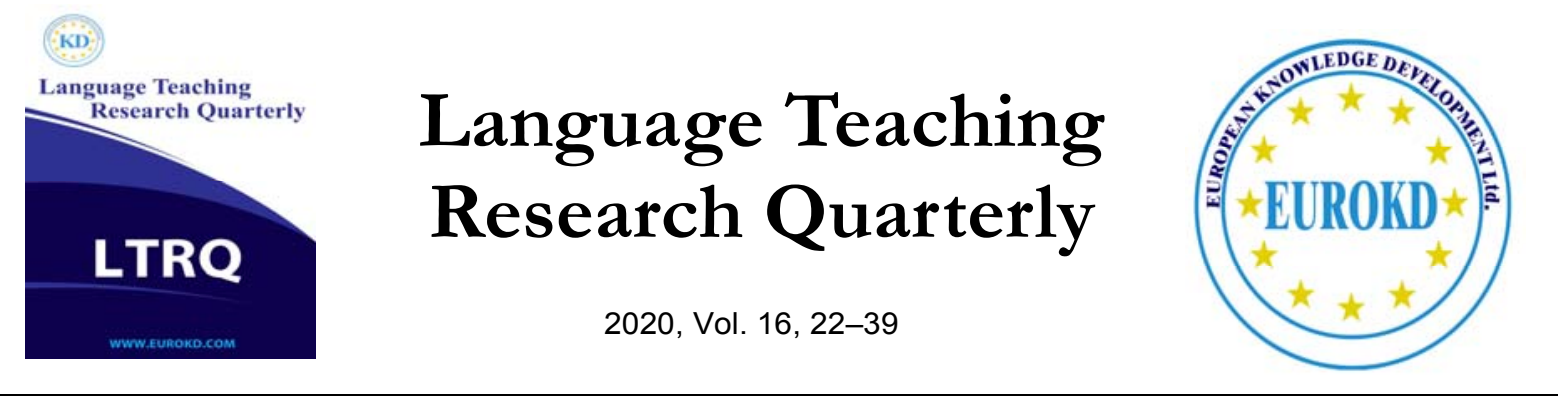

\title{
Modeling AMO Factors Affecting English Teachers' Performance Using System Dynamics
}

\author{
Moloud Mohammadi*, Arefe Amini Faskhodi \\ Department of English, College of Literature, Humanities, and Social Sciences, Science and Research \\ Branch, Islamic Azad University, Tehran, Iran
}

Received 07 February 2020

Accepted 28 March 2020

\begin{abstract}
In the knowledge age, performance evaluation is one of the vital components of each organization, and educational organizations are no exception. Teachers are believed as the single most important factor influencing students' academic success or failure. Considering the pivotal role of teachers, educational systems need to not only be assured that teachers perform at their best to enhance student learning, they also urgently require attempting to identify strengths and weaknesses in teachers' practice for further professional development. The AMO theory of human resource management represents that the three independent system components which characterize an individual are: ability, motivation, and opportunity. Since there are many interactions between and among the components of a system, the system dynamics approach was selected to observe the changes in the behavior of an individual (system) overt time. For the purpose of this study, three types of surveys encompassing both Likert-scaled items and open-ended surveys were developed and then English language experts and teachers were asked to take participate in the process of data gathering. The results indicated that factors of teachers' ability and motivation will affect teachers' performance more than opportunity factors during the next 72 months in an S-shaped manner of behavior.
\end{abstract}

Keywords: System Dynamics, AMO Theory, Simulation, Modeling, Human Behavior, Teacher Performance, EFL Teachers

\section{Introduction}

Owing to living in an era of accountability, it is high time we ensured a quality education. Considering learners' academic achievement as the best evidence for a quality education (Morgan, Hodge, Trepinski, \& Anderson, 2014; Sanders, Wright, \& Horn, 1997), some research 
has been undertaken regarding the investigation of the most beneficial factors in learners' academic success. The outcomes of these studies indicate teachers as an essential part of highlyqualified education (Gasper \& Vieira, 2013; Morgan et al., 2014; Sanders, Wright, \& Horn, 1997).

Becoming aware of the leading role teachers play in learners' academic accomplishment and also in any educational system's attainment is aligned with the requisite for discovering the most dependable solution for the evaluation of teachers' acting and efficiency (Medley, 1982). Teacher evaluation, as a complicated concept entailing a number of variables affecting teachers and teaching, refers to "the systematic assessment of a teacher's performance and/or qualifications in relation to the teacher's defined professional role and the school district mission" (Shinkfield \& Stufflebeam, 1995, p. 86). Moreover, due to its significance for any enterprise or activity, teacher assessment is always necessary. The necessity of evaluating instructors as a means of enhancing professional development, learners' academic accomplishment, and quality guarantee has uncovered the possible advantages of assessments and particularly performance-based assessments, beneficial to both teachers and learners (Danielson \& Marquez, 1998; Delandshere \& Arens, 2003; Haertel, 1991). Having been proved by the contextualized clue in student learning, performance assessment is a stronger instrument to foresee teachers' roles in learners' accomplishments (Darling-Hammond, 2010). Based on the convincing reasons set out by a large body of literature, not only is performance assessment beneficial to students, it is also advantageous to teachers. Sandholtz (2012) claims performance assessment as an indicator of how teachers' conversance and abilities are applied in teaching, reflection, and consequently employment of suitable pedagogical strategies to gain productive teaching. It results in teachers' manipulation of supplementary teaching plans, maintenance of student attainment, and adjustment of their operations regarding the outcomes of assessment (Darling-Hammond, 2010).

Chung (2007) similarly reasons that teaching applicants will be capable of modification of their instruction according to the performance assessment which results from the students' learning perspective. Based on Pecheone and Chung, making use of performance assessment, comprising evidence on real teaching operation, more direct evaluation of teaching ability will be potentially provided (2006). The importance of performance assessment in broadening teachers' subject matter knowledge, ameliorating their classroom management, and their instructional design has been admitted by Darling-Hammond (2010) as well. Importantly, performance assessment helps novice teachers since their understanding of teaching and their practice will be enhanced (Darling-Hammond, 2010). In a similar vein, according to Chung (2007) performance assessment has a positive impact on teachers' professional learning. Yet, almost no evidence is there to announce decisions about two vital system design characteristics one of which is teacher performance measure weights and the other appears to be performance ratings thresholds (Steinberg \& Kraft, 2017). From another perspective, due to a variety of reasons, professional growth is undervalued very often by both institutions' administration and teachers themselves. In fact, a great deal of attention is given to the teacher candidates' English proficiency and 
qualification. In other words, provided that these two requirements are satisfied by teachers, these applicants are considered competent enough to be employed. This might result in teachers' lack of interest in making efforts to get promoted. Besides, a considerable number of teachers are overloaded with their work not only inside the class teaching to their students but also outside the class planning, checking learners' assignments, so on and so forth. As a result, they have no time to update their knowledge.

Lack of interest in professional development may have a number of serious consequences. First, as a result of living in a rapidly changing world, unless our teachers keep up their knowledge up-to-date, what students acquire will be more likely to get outdated even before their graduation and it in turn can affect their future professional lives. In addition, calling teachers qualified does not in fact result in them being qualified (Loeb, 2008). For instance, there are times when teachers' methodology is considered by them as the most pertinent one whereas it might be old-fashioned. For instance, considering the outcomes of a study on the public school teachers in Colombia, the grammar approach was still considered as the best approach to teach English as a foreign language by a number of instructors. Thus, obviously in order to accommodate themselves to the modern pace, teachers are required to be willing to update their knowledge and finely adjust their abilities based on the changing world's requirements. Professional development hence will be the bridge connecting their current position to the point where they need to be.

On the other hand, with respect to the complex nature of language learning and influential variables in this regard, there has been a large body of research making use of system dynamic approaches. Although the approach of system dynamics has been applied to study language and its components (e.g. Dong, 2016; Greenhill, Wu, Hua, Dunn, Levinson, \& Gray, 2017) and a few studies have employed such an approach in the area of education regarding the regional context of the researchers (e.g. Faham, Rezvanfar, Mohammadi, \& Nohooji, 2017; Kasbi, \& Shirvan, 2017); as far as the researchers are concerned, no single study has considered system dynamics approaches in the domain of teacher education, and particularly in the area of teaching English as a Foreign Language (EFL) in their country. Therefore, in order to bridge this gap, this study aims at modeling criteria affecting EFL teachers' performance employing a system dynamic approach.

\section{Literature Review}

In the following all the variables under study will be dealt with conducting a thorough literature review.

\section{Performance}

Organizations tend to improve the staff's performance through influencing their behavior (Sonnentag \& Frese, 2002). Right attitudes accompanying right behavior make individual employees perform desirably; or in fact, act in a way contributing to the organizational goals. Here, performance is defined as objective orientated behavior in an organizational setting. Often an employee's organizational goal-oriented performance, behavior, is assessed in a performance 
evaluation process (Fletcher, 2001). Since it is not the organization that performs but the employees, how to direct individual's behavior towards professional development of EFL teachers is one of the effortful and meanwhile crucial issues in the area of guiding colleagues in human resource management (HRM) (Kozlowski \& Klein, 2000). Identification of the elements affecting employees' behavior and the causal relations appears essential in these regards (Becker $\&$ Gerhart, 1996). Also the reason why positive employees' outcomes do not necessarily eventuate after employing well-instructed HRM practices should be taken into account. According to Campbell, cognitive factors of job performance encompass declarative knowledge including goals and principles, procedural knowledge and skills comprising cognitive skills, physical skills, and interpersonal skills, along with motivation comprising choice to perform as well as level and persistence of effort (Campbell, McCloy, Oppler, \& Sager, 1993). Motivation is possibly clarified as "the processes that account for an individual's intensity, direction and persistence of effort toward attaining a goal” (Robbins, Judge, \& Campbell, 2010, p. 140).

An employee will only perform when he both can and wants to fulfill tasks assigned to him (Delaney \& Huselid, 1996). For example, a mere well-educated researcher deprived of motivation tends to have a poor performance. On the other hand, a highly motivated hairdresser with no experience in flying planes will not succeed in a pilot's job. Furthermore, a corresponding environment, among others' equipment and cooperation, is of high importance without which an employee's knowledge and motivation to accomplish a designated task will possibly doomed to failure. As a result, an employee must be provided with an opportunity to participate. Here, opportunity means every single extraneous factor affecting an individual's performance. In other words, the forces around an individual and his/her motivation tasks empowering or constraining her task performance which are not in the person's direct control must be particularly configured (Blumberg \& Pringle, 1982).

Consequently, Appelbaum, Bailey, Berg, and Kalleberg (2000) emphasize incentives, skills, and opportunity to practice as the three requirements essentials for successfully implementation of an HRM system. Incentives aim at employees' motivation, and skills consist of both declarative and procedural knowledge. This is is not in accordance with Campbell's model. Similarly, people possessing required knowledge, skills, and abilities (KSA) perform to accomplish a given task (Appelbaum et al, 2000). They also need to have motivation and an opportunity for participation. KSA, motivation, and opportunity are the main elements of the so called AMO theory in which performance $\left(\mathrm{P}_{\mathrm{i}}\right)$ of an individual $\mathrm{i}$, is a function $f$ of his/her motivation ability $A_{i}$ to perform, his/her motivation $M_{i}$ to perform, and the opportunity to perform in the job $\mathrm{O}_{\mathrm{i}}$ all of which are relevant to one another according to Boxall and Purcell (2011).

Since 2000, when it emerged, the AMO theory has been acknowledged in HRM related studies (Boselie, Dietz, \& Boon, 2005). Based on the AMO theory, the three components which form individuals' characteristics and determine the success or failure of an organization are ability, motivation, and opportunity. Ability, including an employee's knowledge, skills, and abilities (KSA), refers to the ability to perform responsibilities and is required to be realized in a 
wider sense. Motivation is defined as an important factor in eliciting individuals' performance (Wyatt et al., 1934) and opportunity as an individual's willingness, opportunity, and capacity to perform a task, and more generally the states of nature and also the actions of others (Blumberg \& Pringle, 1982). As mentioned by Purcell et al. (2003), the AMO model can be used to comprehend behavioral processes and potential performance progression.

\section{EFL Teacher Performance}

Although the necessity of teacher evaluation has been admitted by some researchers, the present teacher evaluation methods have been recently criticized for their inefficiency (McGreal, 1988; Peterson, 2000; Prybylo, 1998). According to Danielson and McGreal (2000), the evaluative criteria must be based on the latest findings of educational studies; however, a great number of evaluation methods suffer from serious deficiencies. In fact, they utilize outdated and inadequate evaluative criteria which lack appropriate values and assumptions about good teaching as well as precision in performance evaluation (Danielson \& McGreal, 2000). A further criticism is due to their ignorance about the contexts, processes, and reflection (Bunch, Aguirre, \& Téllez, 2009).

Particularly the present evaluation methods applied in the researchers' countries' educational systems do not result in quality education, learners' academic achievement, and professional development. They, in fact, fail to achieve the desired purposes for which they were employed (Navidinia, Kiani, Akbari, \& GhafarSamar, 2013). Considering what was just mentioned, this study is an attempt to address some of the criticisms leveled at the previous EFL teacher evaluation methods applied in the researchers' educational context through provision of a performance assessment scheme.

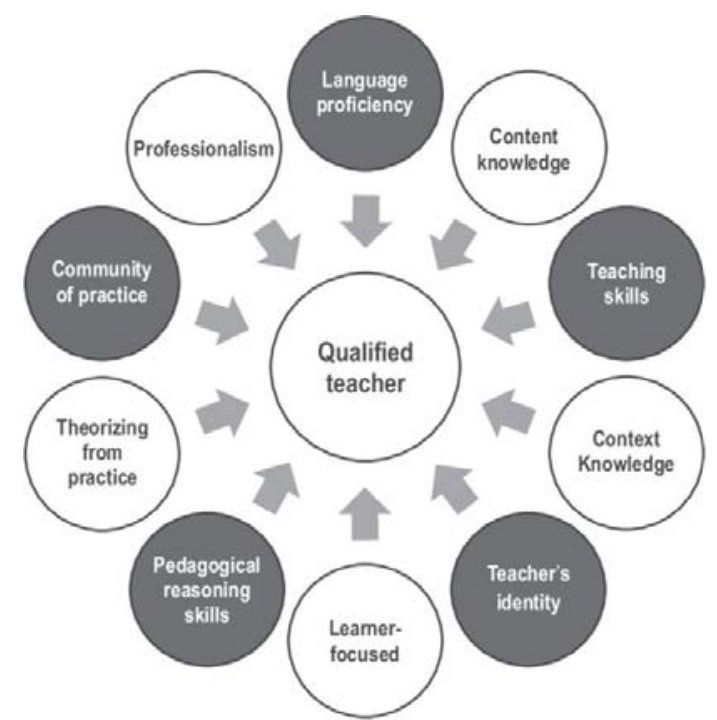

Figure 1. Qualified Teacher Concept (based on Richards, 2010)

As mentioned by Novozhenina and López Pinzón (2018), the term qualified teacher, in daily life, education policies, and also academic literature is still vague, since providing an exact 
definition of qualities constituting a qualified teacher is difficult. First, the concept varies from one context to another. For instance, a university professor and a first-grade teacher do not obviously have the same characteristics. Another reason is that a great number of details must be considered in the description which might not be a quite difficult task. In addition, the definition of a good teacher may differ from person to person. In an attempt to unite as many characteristics as possible by Richards (2010), he concluded ten characteristics defining a qualified teacher (see Figure 1). Nevertheless, this description is not comprehensive mentioning that it grasps the notion of a good teacher from the western perspective teaching (Richards, 2010). Such an idea of a good teacher is noticeably wide considering plenty of various features. Thus, fully developing all of them might appear quite challenging, since it might be quite time consuming (see figure 1). Meanwhile, teacher quality has been defined by some other experts in a simpler manner. For instance, from the point of view of Kunter, Klusmann, Baumert, Richter, Voss, and Hachfeld (2013) professional competence includes "the skills, knowledge, attitudes, and motivational variables that form the basis for mastery of specific situations" (p. 3).

\section{System Dynamics}

The word system derived from the Latin word Sistema referring back to the Greek word Sistema is one of the controversial words owing to its approximately subjective nature. In fact, while the word may remind some people of the constructivist perspective or the reality independent of human mind, it may be employed in a successful manner by some other individuals even without fully understanding it (Skyttner, 1996). In 1971, a system was defined as anything sufficiently unitary for having a name. There also exists a scientific definition by Ackoff (1971) based on which a system is either a conceptual or physical entity encompassing components interdependent on one another, fulfilling the subsequent circumstances: First, the behavior of the sum of the elements is influenced by that of one single element. Second, the whole and a single element's behavior and effects are dependent on one another. Third, they influence the behavior of the whole through the subgroup's structure they are constructed of. As a result, there is a coordination of a functional work divided among a system's components distinguishing a system from an ordinary assembly whose set of components have the same functionality (Skyttner, 1996). Those properties of a system which drive from the current connections among the system's elements, their interactions, and fit are possible to be dealt with satisfactorily from a mere holistic perspective. Nevertheless, in defectively organized systems, although each single component performs at its best considering their own objectives, hardly does the system as a whole accomplish the same level of performance considering its objectives (Ackoff, 1971).

In the early twentieth century, structuralism was emerged based on Saussure's beliefs. Saussure, studying how it was not possible to reduce the whole to its elements, believed that it was impossible for the society as a self-organized structure functioning based on certain regularities to be deliberately and consciously created (Skyttner, 1996). Considering the holistic ideology, parallel with the structuralism, the idea of universal social science was developed by Schumpeter whose main idea was elimination of the borders among the disciplines (Michaelides 
\& Milios, 2009). Forrester (1989) studying inventory management developed industrial dynamics for the first time in the 1960s in which concepts including system, feedback, control, and dynamics were transferred from the fields of engineering and physics to the social systems like organizations as a result of Forrester's considerable work, which in turn resulted in the establishment of a new technique used for organizations to identify their managerial policies (Lane \& Sterman, 2011).

However, industrial dynamics was later employed in other complex subjects and was transferred to the more famous social system dynamics whose popularity was to some extent due to its being the basis for the evolutionary models since the 1970s (Meadows, Meadows, Randers, $\&$ Behrens, 1972). Since dynamics equals to change over time, a dynamic system is a system whose variables interact with one another resulting in their change over time. On the other hand, were the system dynamics, a technique employed to study the way how the system behavior changes over time, relevant to the fields of management and engineering from the beginning, it would have gradually changed into be beneficial to the variety of fields, including social, economic, physics, chemical, biological, and ecological systems, as well as a research discipline regarding Massachusetts Institute of Technology since the early 1960's. A great number of the current vital names, for instance, the Meadows, Nancy Roberts, Richmond and Peterson, as well as Senge were impressed by Forrester's disciples (Chen \& Stroup, 1993). From another perspective, since the term dynamics is applied due to the changeability of system behavior as its structure's principal function, system dynamics is possible to be made use of in order to understand how the behavior of the whole might be affected by a number of structural changes. Thus, the system analysis is conducted deliberately changing the ordinary conditions individually (Martin, 1997).

Focusing on types of models, quantitative models of strategic problems have been long utilized in the discipline of system dynamics in order for dynamics of a problem to be stimulated and this in turn might help generate insights into policies to enhance system behavior. Sterman (2000) defined system dynamics as a method of improving the process of learning in intricate environments and for "developing management flight simulators, often computer simulation models, to help us learn about the dynamics complexity, understand the sources of policy resistance, and design more effective policies" (p.4). According to Senge (2006), system dynamics investigates complicated systems encompassing human systems such as families, organizations, cities, and nations whose infinite complexity will be revealed by a close analysis of the relationships among their members. Considering a systems approach as a solution to a problem, it is realized that there is no single complete theory. However, problems are considered comprehensively here. Many daily complex tasks such as driving cars are dealt with effectively.

In order to identify influential concepts and categories in a phenomena, particularly in the fields of social sciences, psychology, and alike various methods are applied by system dynamics. This dynamic approach first proposed by Forrester (2000) in industrial work, later was employed in other fields in particular in social sciences and economics. Rodriguez and Paucar (2005) believe that a system's behavior can be anticipated by the dynamics models of the system. They 
also introduce the two main goals of the system dynamics approach as first, description of the behavior of the system regarding its structure and behavior; and second, propositions about changes in the structures or/and policies to improve the system behavior (Coyle, 1998). The purpose of modeling in the system dynamics approach is to gain a perception of how the system behaves, which in turn could be a possible method for policies and strategies to be designed to improve the system performance over time. There are two principal approaches for implementing the dynamical system of the system. The top-down approach is theory-oriented whose purpose of modeling process is mainly analysis and examination of issues. On the other hand, the collected data and problem are the basis of the bottom-up approach (Kopainsky, 2005).

The existence of multiple teaching and teacher-related factors accounts for the serious challenges caused by the dynamics to the policy makers. Consideration of uncertain complex dynamic aspects in the HRM policy formulation process, resulted from the changes arising in the market value and market needs, is imperative. In retrospect, these sophisticated challenges and issues should have been addressed in teacher performance policy formulation and evaluation. Being specifically suitable for modeling and simulation of complex real world phenomena (Garcia, 2009), the system dynamics approach applied in this study intends to stimulate EFL teacher performance. Moreover, a reflection on professional development will be presented and a number of questions will be dealt with: How do in-service teachers with different experience and backgrounds respond to interference in their teaching process? How does performance take place? Which factors have the most influential effects on teachers' performance? How both physical and psychological states of EFL teachers should be considered? It is worth mentioning that the suggested causal loop structures provide a platform for system dynamics approaches to EFL teaching modeling and simulation. The causal loop structures are probably beneficial to the analysts and decision makers in the fields of HRM, teaching, EFL teaching, and also the policy makers.

As this is a mixed methods study, the main research questions are the hypotheses extracted from the causal loops. In the current study, the researchers aim at answering the following questions:

RQ1. How does teachers' performance change during the next 72 months?

$\mathrm{RQ}_{2}$. Does the ability factor have any statistically significant effects on their performance during the next 72 months?

RQ3. Does the motivation factor have any statistically significant effects on their performance during the next 72 months?

$\mathrm{RQ}_{4}$. Does opportunity factor have any statistically significant effects on their performance during the next 72 months?

\section{Methodology}

The present study is an applied research in terms of its both purpose and survey method. Since it is a mixed-methods study, in which the main goal is to study the dynamism of the performance 
system through the extraction of the variables and their manner of interaction, the researchers conducted the stages of qualification, quantification, and merging.

\section{Participants}

For the purpose of model validation, data were collected from 63 EFL instructors at university levels. In other words, the data were collected from lecturers, teaching assistants, educators, professors, and elites in the form of online surveys. The surveys were emailed to the participants asking them to submit their responses by the end of the week. The participants provided answers to various multiple choice and one-liner questions based on different aspects of their personal and professional lives.

\section{Instruments and procedures}

During the processes of data collection and data integration, three types of researcher-made surveys were developed and implemented. In the first questionnaire, the participants were expected to determine the most influential factors affecting EFL teachers' performance. In the second one, they were supposed to verify the proposed model. Finally, in the third one, they were asked to determine the weight the relationships. The reliability was reported to be $0.68,0.77$, and 0.71 respectively in the surveys. System dynamics is suitable for studying teachers' performance structure due to a variety of reasons. First, the purpose of SD is to study the complexities of social dynamic systems. In addition, SD can be used to study the process of system development with respect to endogenous factors. And eventually, it can be used to simulate the dynamics of the system during a long-term administration. The diagram of building a model using the system dynamical approach is shown in Fig. 2

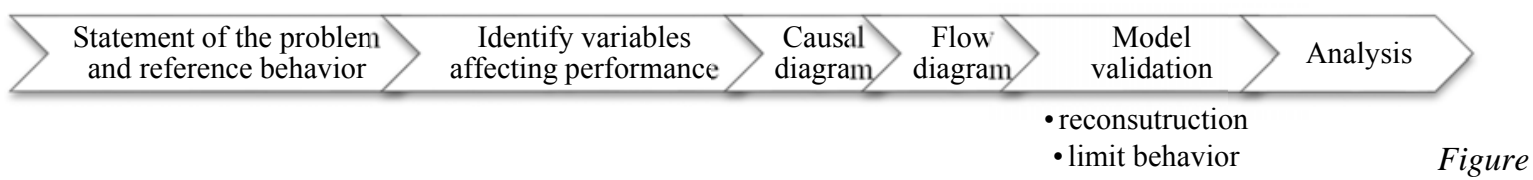

2. Stages of Building a Model in System Dynamics Approach

a. Statement of problem and reference behavior: Problem definition is the most vital stage in the system dynamics modeling (Sterman, 2000). It provides the process of modeling with a clear purpose which is a key factor determining the success of a modeling process (Richmond, 1997; Sterman, 2000). Talking about a problem definition, owing to the dynamic difficulty, selection of the key factors, and drawing the reference modes, a verbal statement has been mostly emphasized.

b. Identification of variables affecting performance: An in-depth literature review in the fields of organizational behavior, educational and social psychology, and management science was conducted in order to identify relevant moderator and mediator variables. 
c. Causal diagram: The mental model of causes and effects was proposed using the Vensim PLE 7.3. Some of the advantages of Vensim are as follows: The first advantage is causal tracing, which helps the user discover which variables cause a particular variable to change. The second is subscripting enabling the user to repeat a structure within a system. The third is Vensim subscripting language which allows the construction of advanced array models.

d. Model calibration: A stage in which Vensim accepts a time series data collected in the real world to perform system validation. Here the cost effectiveness is of high importance which means the software is fully functional system dynamics software and is free of charge unless it is used for business purposes.

e. Flow diagram: The flow diagram was extracted from the causal diagram making use of Vensim PLE 7.3 in order to represent the detailed structure of the flow of the system in the form of its finely-detailed policy structure.

f. Model validation: System dynamics models should be validated more strictly in comparison with other methodologies and techniques regarding the disciplines of management science and econometrics. Inevitably, there exists no model capable of representing the ultimate truth. However, the purpose of evaluating the validity of a model employing a variety of tests is to provide policy analysts with a more appropriate instrument.

g. Validation of simulation models in system dynamics consists of two types of validity tests; first, structural validity tests (i.e. to check whether the structure of the model is an adequate representation of the real structure) and second, behavior validity tests (i.e. to check the capability of the mole for producing a desirable output behavior).

h. Analysis: In this study, during the process of quantification, running the model, and sensitivity analysis, regression analysis was performed using SPSS 19 in order to extract the formulas. Then, the simulation performed and the authors represented the results.

\section{Data analysis}

Data analysis was done applying both SPSS and Vensim PLE which will be further elaborated in the following sections.

\section{Results}

As pointed out earlier, the present study aims to model the factors affecting EFL teacher performance. To model the existing factors affecting teachers' performance, the authors first identified the key variables determining the behavior of the system and then established their dependencies on each other. Figure 3 shows the causal loop diagram of the factors affecting EFL teachers' performance. 


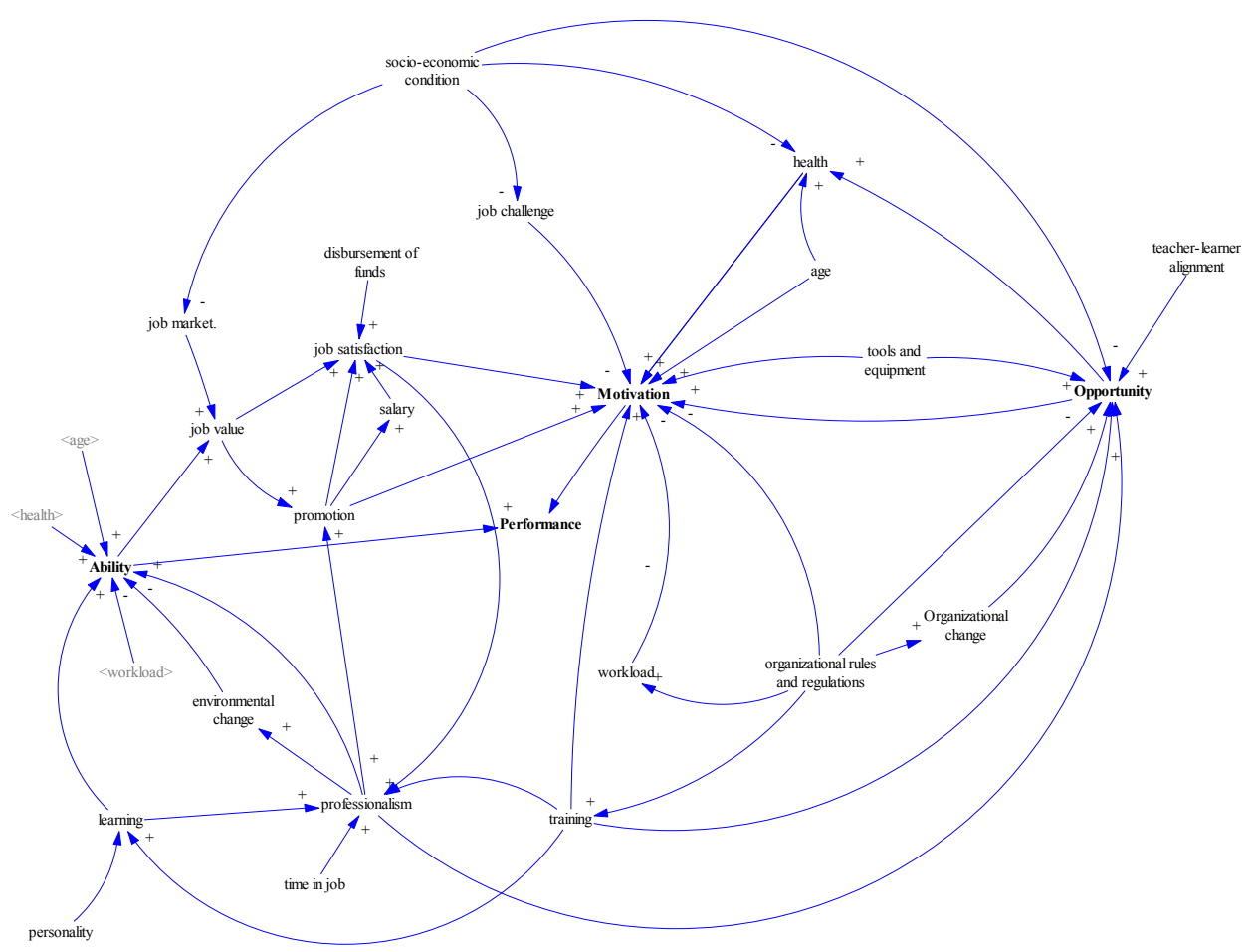

Figure 3. The Causal-Loop Diagram of Factors Affecting Teacher Performance

RH1: EFL performance does not statistically change over a period of 72 months.

In this scenario, one can observe that teachers' performance follows an S-shaped curve based on which, in the first 24 months, teachers' performance improves slowly and then due to in-service and personal training this growth happens at a greater rate during the second 24 months. Finally, during the last 24 months, the growth rate decreases. It is worth mentioning that such an increase in the total performance of EFL teachers is mainly dependent on the changes of their ability and motivation during this period of time (figure 4).

performance

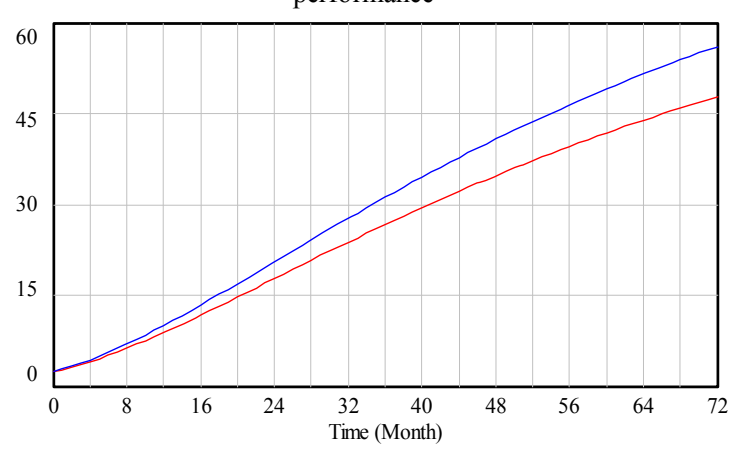

performance : run $\longrightarrow$ performance : base

Figure 4. EFL Teachers' Performance over a Period of 72 Months

RH2: EFL teachers' ability does not statistically change over a period of 72 months. 
Changes in the ability of EFL teachers follow a goal-seeking shape. Such a shape represents that teachers' ability grows to the point it reaches to its highest level (i.e. professionalism). Then, it seems necessary for teachers to adjust their ability to the modern, everyday changing requirements as well as necessities of the field. Focusing on the proposed model, it can be concluded that EFL teachers' ability has a statistical significant effect on their performance in a goal-seeking manner.

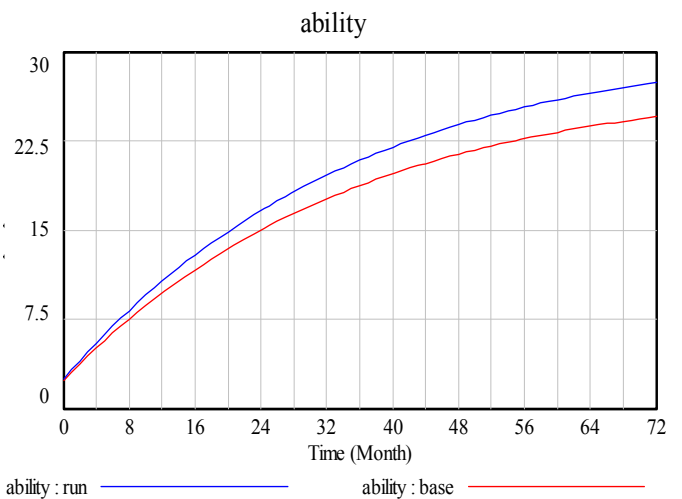

Figure 5. EFL Teachers' Ability over a Period of 72 Months

RH3: EFL teachers' motivation does not statistically change over a period of 72 months.

Teachers' motivation follows an exponential growth. In other words, the growth is proportional and here, it is directly referred to the proportion of teachers' ability and opportunity. Regarding the proposed model, EFL teachers' motivation has a statistical significant effect on their performance which is predictable based on an exponential curve.

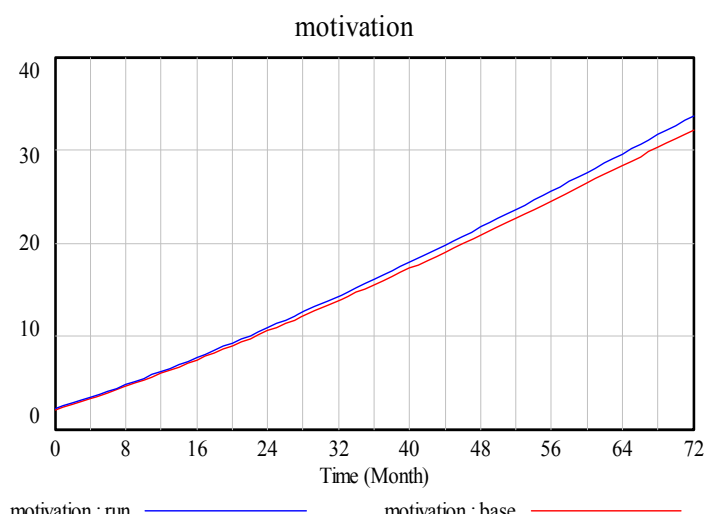

Figure 6. EFL Teachers' Motivation over a Period of 72 Months

RH4: EFL teachers' opportunity does not statistically change over a period of 72 months.

As represented in the previous section, opportunity factors do not directly affect teachers' performance. Rather, they affect the motivation factor in a goal-seeking manner based on which 
EFL teachers' opportunity increases in a way that it reaches to a specific maximum level, then there should be another opportunity case to improve their motivation.

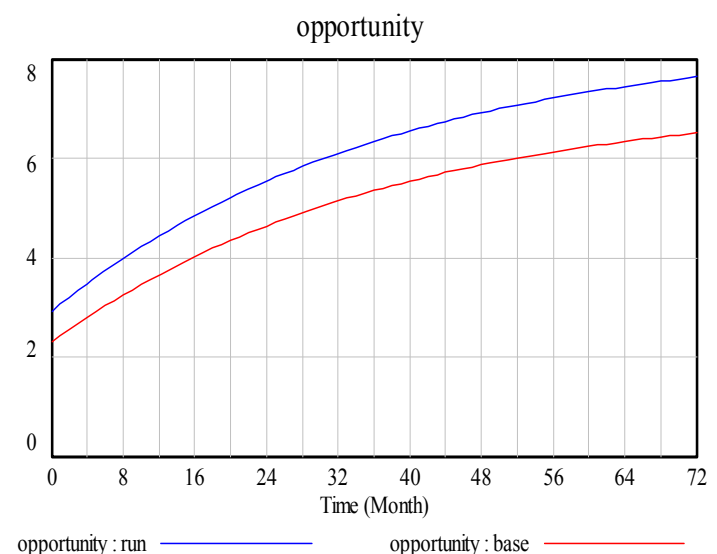

Figure 7. EFL Teachers' Opportunity over a Period of 72 Months

\section{Discussion}

This study intended to build a detailed model of the effects of AMO factors and EFL teachers' performance using the system dynamics approach. This is the study of how various AMO factors influence teachers' performance over time based on the proposed model. Not only is the approach relevant to the practitioner, but it also contributes to organizational and management research by bridging the existing research gap. The system dynamics approach was used for this study since it can handle dynamic systems with complex nonlinearities, delays, and feedback processes (Sterman, 2000) and this feature, according to Vancouver and Weinhardt (2012), facilitates understanding of and predicting human behavior. However, to the best of the authors' knowledge, there is no single system dynamics model explicitly based on the well-established AMO theory in management and organizational science. According to Vancouver and Weinhardt (2012), one reason is the scarce use of computational modeling in management and organizational science for supporting theoretical development or refinement, specifically considering the micro level of analysis.

There are different techniques to model mental processes and human behavior. PérezPinillos, Fernández, and Borrajo (2011) presented a model of human reasoning making use of the planning domain definition language (PDDL) and based on automated planning, integrating emotions, drives, preferences, and personality traits. Zadeh (1973) used the fuzzy logic model according to which simple rules in the form IF $\mathrm{x}$ THEN $\mathrm{y}$ with $\mathrm{x}$ and $\mathrm{y}$ are considered as fuzzy variables. And finally system dynamics (Sterman, 2000) takes advantage of causal loops, stock and flow diagrams. System dynamics provides a full methodology from the system representation to the simulation model. The causal loop diagram represents the system qualitatively. The elements of the system and their relations are visualized by the diagrams. Such diagrams with an obvious structure are more likely to be understood and interpreted even by non-expert users in system dynamics. Therefore, discussion among scholars from a variety of 
fields such as psychology, management science, or organization theory is facilitated. Furthermore, the social psychology and behavioral science models applied for mediator and moderator variables to be identified and analyzed (Baron \& Kenny, 1986) can be converted into causal loop diagrams which are the basis of the stock and flow diagram, the quantitative representation of the model. In the formal transformation process from the causal loop diagram to the stock and flow diagram, the consistency between quantitative model and the qualitative model must be ensured.

\section{Conclusion}

The current study developed a system dynamics model of teacher performance based on the AMO theory. In the model, the causal interdependencies among ability (KSA), motivation, and opportunity are presented. In addition, the way other factors influence the AMO variables are also illustrated. Similarly, arguing for the importance of defining the concept of standards to evaluate teacher performance, Cochran-Smith (2001) admits that in order to develop a valid teacher assessment, it is important to describe knowledge, skills, and dispositions which are necessary for teacher candidates to accomplish in detail. Accordingly, a system dynamics model was developed to explore the link between the AMO factors and job performance. According to this theory, performance is the role of an employee's ability to perform, or in other words, motivation to perform, and the opportunity to participate.

Applying such a hybrid model permits us to investigate the influence of HRM policies and practices on the whole organization. For instance, it will be possible to recognize whether incentives, employed in a great number of organizations for employees' motivation towards performance, increase the organizational performance. Clearly, an employee granted an incentive will be affected in a positive way. On the other hand, the danger of creating a culture of jealousy in which the results are in contrast with the good intentions should be taken into consideration. One method used for developing theories is simulation (Davis, Eisenhardt, \& Bingham, 2007). Owing to the fact that causal loop diagrams result in the ease of critical discussions on relevant factors and their interrelations by scholars in various fields, management science and behavioral science are no exception and are likely to apply the system dynamics model developed in this study. One of the benefits of these types of diagrams is that, in general, their interpretation is easier in comparison to other methods including subjective fuzzy definitions (Morris, Ross, \& Ulieru, 2010). Other goal oriented empirical studies identifying the direct relationships between variables can be initiated based on the resulted model in this study. However, the model, simplifying the real world, is certainly incomplete and faulty; and therefore, is highly probable to be optimized in further studies. For instance, since an employee's personality is modeled in a primitive fashion, other studies could consider the integration of desires and beliefs as well (Bratman, 1999). If the model is extended more into work environments, it will probably help us understand the extent to be invested in work environments.

Although disaggregation of these elements could lead to a more accurate model, it is crucial to consider that more elements do not necessarily result in a more reliable model. A higher 
number of elements results in a greater number of relations. This, in turn, increases validation efforts significantly. Validation of the model has already been very complex and the model is not a fully validated one. Due to the fact that the scientific literature in the fields of management and psychology does not always clearly indicate how and to what extent variables affect one another and there is a lack of longitudinal empirical studies, these are still open fields for further research and the findings will be reflected in the model validation. Moreover, the current conditions of the model are consistent with what Peter Boxall and John Purcell stated according to which contingency models which are too thick should be avoided. What is necessary, in fact, is the evolvement of models explaining most of the vital connections (Boxall \& Purcell, 2000).

\section{References}

Ackoff, R. L. (1971). Management misinformation system. Management Science, 14(4), B147-B156.

Appelbaum, E., Bailey, T., Berg P., \& Kalleberg, A. L.(2000). Manufacturing advantage. Cornell University Press, Ithaca, NY, USA.

Baron, R. M., \& Kenny, D. A. (1986). The moderator mediator variable distinction in social psychological research: Conceptual, strategic, and statistical considerations. Journal of Personality and Social Psychology, 51(6), 11731182.

Becker, B. E., \& Gerhart, B.(1996). The impact of human resource management on organizational performance: Progress and prospects. Academy of Management Journal, 39(4), 779-801.

Blumberg, M. and Pringle, C.D. (1982). The missing opportunity in organizational research: some implications for a theory of work performance. Academy of Management Review, 7(4), 560-9.

Blumberg, M., \& Pringle, C. D. (1982). The missing opportunity in organizational research: Some implications for a theory of work performance. The Academy of Management Review, 7(4), 560-569.

Boselie, P., Dietz, G., \& Boon, C. (2005). Commonalities and contradiction in research on human resource management and performance. Human Resource Management Journal, 15(3), 67-94.

Bosse, T., Memon, Z. A., \& Treuer, J.(2007). A two-Level BDI-Agent model for theory of mind and its use in social manipulation. Proceedings of the AISB 2007 Workshop on Mindful Environments 2007 (pp. 335-342), Newcastle, UK.

Boulding, K. E. (1985). The World as a Total System. Beverly Hills: Sage Publication.

Boxall, P., \& Purcell, J. (2000). Strategic human resource management: Where have we come from and where should we be going? International Journal of Management Reviews, 2(2), 183-203. doi:10.1111/14682370.00037

Boxall, P., \& Purcell, J. (2011). Strategy and human resource management. Palgrave Macmillan, New York, NY, USA.

Bratman, M. E. (1999). Intention, plans, and practical reason. MA: Harvard University Press.

Bunch, G. C., Aguirre, J. M., \& Téllez, K. (2009). Beyond the scores: Using candidate responses on high stakes performance assessment to inform teacher preparation for English learners. Issues in Teacher Education, 18(1), 103-128.

Campbell, J. P., McCloy, R. A., Oppler, S. H., \& Sager, C. E. (1993). A theory of performance. Personnel selection in organizations, 3570, 35-70.

Chen, D., \& Stroup, W. M. (1993). General system theory: Toward a conceptual framework for science and technology education for all. Journal of Science Education and Technology, 2(3), 447-459. doi: 10.1007/BF00694427 
Chung, R. R. (2007). Beyond the ZPD: When do beginning teachers learn from a high-stakes portfolio assessment? The Annual Meeting of the American Educational Research Association. Chicago, IL. Retrieved from https://scale.stanford.edu/system/files/RRChungAERA2007_0.pdf

Cochran-Smith, M. (2001). The outcomes question in teacher education. Teaching and Teacher Education, 17(5), 527-546.

Coyle, G. (1998). The practice of system dynamics: milestones, lessons and ideas from 30 years' experience. System Dynamics Review: The Journal of the System Dynamics Society, 14(4), 343-365.

Danielson, C., \& Marquez, E. (1998). A collection of performance tasks and rubrics: High school mathematics. Larchmont, NY: Eye on Education.

Danielson, C., \& McGreal, T. (2000). Teacher evaluation to enhance professional practice. Alexandria, Virginia: Association for Supervision and Curriculum Development (ASCD).

Darling-Hammond, L. (2010). Evaluating teacher effectiveness: How teacher performance assessments can measure and improve teaching. Center for American Progress.

Davis, J. P., Eisenhardt, K. M., \& Bingham, C. B. (2007). Developing theory through simulation methods. Academy of Management Review, 32(2), 480-499.

Delandshere, G., \& Arens, S. A. (2003). Examining the quality of evidence in preservice teacher portfolios. Journal of Teacher Education, 54(1), 57-73.

Delaney, J. T. \& Huselid, M. A. (1996). The Impact of Human Resource Management Practices on Perceptions of Organizational Performance. Academy of Management Journal, 39(4), 949-969.

Dong, J. (2016). A dynamic systems theory approach to development of listening strategy use and listening performance. System, 63, 149-165. DOI: https://doi.org/10.1016/j.system.2016.10.004

Faham, E., Rezvanfar, A., Mohammadi, M., Seyed, H., \& Rajabi-Nohooji, M. (2017). Using system dynamics to develop education for sustainable development in higher education with the emphasis on the sustainability competence of students. Technological Forecasting and Social Change, 123(C), 307-326. doi:10.1016/j.techfore.2016.03.023

Fletcher, C. (2001). Performance appraisal and management: The developing research agenda. Journal of Occupational and Organizational Psychology, 74, 473-487.

Forrester, J. W. (1961). Industry dynamics. Cambridge: Massachusetts.

Forrester, R. (2000). Empowerment: Rejuvenating a potent idea. Academy of Management Executive, 14(3), 67-80.

Forresterm J. W. (1989). The system dynamics national model: Macrobehavior from microstructure. In P.M. Milling and E.O.K. Zahn (eds) Computer-based Management of Complex System (pp.) Springer: Berlin. doi:10.1007/978-3-642-74946-9_1

Garcia J. M. (2009). Theory and Practical Exercises of System Dynamics. Full reviewed, first edition in 2006, Juan M. Garcia, Barcelona, Spain.

Gasper, M. F., \& Vieira, C. R., (2013). Plenattitude teacher evaluation for teacher Effectiveness and well-being with neuro-linguistic programming. US-China Education Review, 3(1), 1-17.

Greenhill, S. J., Wu, C. H., Hua, X., Dunn, M., Levinson, S. C., \& Gray, R. D. (2017). Evolutionary dynamics of language systems. Proceedings of the National Academy of Sciences, 114(42), E8822-E8829.

Haertel, E. H. (1991). Chapter 1: New Forms of Teacher Assessment. Review of research in education, 17(1), 3-29.

Morgan, G. B., Hodge, K. J., Marie Trepinski, T., \& Anderson, L. W. (2014). The stability of teacher performance and effectiveness: Implications for policies concerning teacher evaluation. Education Policy Analysis Archive, 22(95), 1-21.

Johnson, R. B., Onwuegbuzie, A. J., \& Turner, L. A. (2007). Toward a definition of mixed methods research. Journal of mixed methods research, 1(2), 112-133. 
Kasbi, S., \& Shirvan, M. E. (2017). Ecological understanding of foreign language speaking anxiety: emerging patterns and dynamic systems. Asian-Pacific Journal of Second and Foreign Language Education, 2(1), 1-20.

Kopainsky, B. (2005). A system dynamics analysis of socio-economic development in lagging Swiss regions. ETH Zurich.

Kozlowski, S. W., \& Klein, K. J. (2000). A multilevel approach to theory and research in organizations: Contextual, temporal, and emergent processes.

Kunter, M., Klusmann, U., Baumert, J., Richter, D., Voss, T., \& Hachfeld, A. (2013). Professional competence of teachers: Effects on instructional quality and student development. Journal of Educational Psychology, 105(3), 805-820. doi: 10.1037/a0032583.

Lane, D. J. \& Sterman J. D. (2011). Profiles in Operations Research: Jay Wright Forrester. In S. Gass And A. Assad, Profiles in Operations Research: Pioneers and Innovators (pp. 363-386). New York: Springer.

Loeb, S. (2008). Teacher quality: Improving teacher quality and distribution. Washington DC: National Academy of Education White Paper Series.

Martin, L.A. (1997). The first step, prepared for the MIT System Dynamics in Education Project under the supervision of Dr. Jay W. Forrester, Massachusetts Institute of Technology.

McGreal, T. L. (1988). Evaluation for enhancing instruction: Linking teacher evaluation and staff development. Teacher Evaluation: Six Prescriptions for Success, 1-29.

Meadows, D. H., Meadows, D. H., Randers, J., \& Behrens III, W. W. (1972). The limits to growth: A report to the club of Rome. New York: Universe books.

Medley, D. M. (1982). Teacher competency testing and the teacher educator. Association of Teacher Educators.

Michaelides, P., \& Milios, J. (2009). Joseph Schumpeter and the German Historical School. Cambridge Journal of Economics, 33(3), 495-516.

Morris, A., Ross, W., \& Ulieru, M. (2010). A system dynamics view of stress: Towards human-factor modeling with computer agents. 2010 IEEE International Conference on Systems, Man and Cybernetics(pp. 4369-4374). IEEE, Istanbul, doi: 10.1109/ICSMC.2010.5642412

Navidinia, H., Kiani, G. R., Akbari, R., \& Ghaffar Samar, R. (2015). EFL teacher performance evaluation in Iranian high schools: Examining the effectiveness of the status quo and setting the Groundwork for developing an alternative model. The International Journal of Humanities, 21(4), 27-53.

Pecheone, R., \& Chung, R.R. (2006). Evidence in teacher education: The performance assessment for California teachers. Journal of Teacher Education, 57(1), 22-36.

Pérez-Pinillos, D., Fernández, S., \& Borrajo, D. (2011). Modeling motivations, personality traits and emotional states in deliberative agents based on automated planning. International Conference on Agents and Artificial Intelligence (pp. 146-160). Springer, Berlin, Heidelberg.

Peterson, K. D. (2000). Teacher evaluation: A comprehensive guide to new directions and practices (2 ${ }^{\text {nd }}$ Ed.), Thousand Oaks, CA: Corwin Press.

Prybylo, D. (1998). Beyond a positivistic approach to teacher evaluation. Journal of School Leadership, 8, 558-583.

Purcell, J, Hutchinson, S., Kinnie, N., Rayton, B. and Swart, J. (2003). Understanding the People and Performance Link: Unlocking the Black Box. London: CIPD Publishing.

Richards, J. C. (2010). Competence and performance in language teaching. RELC journal, 41(2), 101-122.doi: $10.1177 / 0033688210372953$

Richmond, B. (1997). The Strategic Forum: aligning objectives, strategy and process. System Dynamics Review, 13(2), 131-148.

Robbins, S. P., Judge, T. A., \& Campbell, T. T. (2010). Organizational behavior. Pearson Education, Essex, UK. 
Rodríguez-Ulloa, R., Paucar-Caceres, A. (2005). Soft System Dynamics Methodology (SSDM): A Combination of Soft Systems Methodology (SSM) and System Dynamics (SD). Systemic Practice and Action Research, 18(3), 303-334. doi:10.1007/s11213-005-4816-7

Sanders, W. L., Wright, S. P., \& Horn, S. P. (1997). Teacher and classroom context effects on student achievement: Implications for teacher evaluation. Journal of Personnel Evaluation in Education, 11(1), 57-67.

Sandholtz, J. H. (2012). Predictions and performance on the PACT teaching event: Case studies of high and low performers. Teacher Education Quarterly, 39(3), 103-126.

Senge, P. (2006). The fifth discipline: the art and practice of the learning organization (2nd ed.). London: Random House.

Shinkfield, A. J., \& Stufflebeam, D. L. (1995). School professionals' guide to improving teacher evaluation systems. In Teacher Evaluation (pp. 81-172). Kluwer Academic Publishers, Springer, Dordrecht. doi:10.1007/978-94009-1796-5_3

Skyttner,L. (1996). General systems theory: An introduction. Basingstoke: Macmillan Press.

Sonnentag, S., \& Frese, M. (2002). Performance concepts and performance theory. Psychological Management of Individual Performance, 23(1), 3-25.

Steinberg, M. P., \& Kraft, M. A. (2017). The sensitivity of teacher performance ratings to the design of teacher evaluation systems. Educational Researcher, 46(7), 378-396.

Sterman, J. D. (2000). Business dynamics systems thinking and modeling for a complex world. McGraw-Hill, Boston, MA, USA.

Sterman, J. D. (2002). All models are wrong: Reflections on becoming a systems scientist. System Dynamics Review, 18(4), 501-531.

Vancouver, J. B., \& Weinhardt, J. M. (2012). Modeling the mind and the milieu: Computational modeling for micro-level organizational researchers. Organizational Research Methods, 15(4), 602-623.

Wyatt, S., Frost, L. and Stock, F.G.L. (1934). Incentives in Repetitive Work: A Practical Experiment in a Factory. London: His Majesty's Stationery Office.

Zadeh, L. A. (1973). Outline of a new approach to the analysis of complex systems and decision processes. IEEE Transactions on systems, Man, and Cybernetics, (1), 28-44. doi:10.1109/TSMC.1973.5408575

Novozhenina, A., \& López Pinzón, M. M. (2018). Impact of a professional development program on EFL teachers' performance. How, 25(2), 113-128. 